\title{
Phenotypic and histochemical traits of the interaction between Plasmopara viticola and resistant or susceptible grapevine varieties
}

\author{
Silvia Laura Toffolatti", Giovanni Venturini, Dario Maffi and Annamaria Vercesi
}

\begin{abstract}
Background: Grapevine downy mildew, caused by Plasmopara viticola, is a very serious disease affecting mainly Vitis vinifera cultivated varieties around the world. Breeding for resistance through the crossing with less susceptible species is one of the possible means to reduce the disease incidence and the application of fungicides. The hybrid Bianca and some of its siblings are considered very promising but their resistance level can vary depending on the pathogen strain. Moreover, virulent strains characterized by high fitness can represent a potential threat to the hybrid cultivation.

Results: The host response and the pathogen virulence were quantitatively assessed by artificially inoculating $\mathrm{cV}$ Chardonnay, cv Bianca and their siblings with P. viticola isolates derived from single germinating oospores collected in various Italian viticultural areas. The host phenotypes were classified as susceptible, intermediate and resistant, according to the Area Under the Disease Progress Curve caused by the inoculated strain. Host responses in cV Bianca and its siblings significantly varied depending on the $P$. viticola isolates, which in turn differed in their virulence levels. The fitness of the most virulent strain did not significantly vary on the different hybrids including Bianca in comparison with the susceptible cv Chardonnay, suggesting that no costs are associated with virulence. Among the individual fitness components, only sporangia production was significantly reduced in cv Bianca and in some hybrids. Comparative histological analysis revealed differences between susceptible and resistant plants in the pathogen diffusion and cytology from $48 \mathrm{~h}$ after inoculation onwards. Defence mechanisms included callose depositions in the infected stomata, increase in peroxidase activity, synthesis of phenolic compounds and flavonoids and the necrosis of stomata and cells immediately surrounding the point of invasion and determined alterations in the size of the infected areas and in the number of sporangia differentiated.
\end{abstract}

Conclusions: Some hybrids were able to maintain an intermediate-resistant behaviour even when inoculated with the most virulent strain. Such hybrids should be considered for further field trials.

Keywords: Disease resistance, Oomycetes, Pathogen fitness

\section{Background}

Plasmopara viticola (Berk. et Curt.) Berlese and De Toni is an obligate parasite, able to biotrophically grow inside the susceptible tissues of species belonging to the genus Vitis and particularly of the extremely susceptible Vitis vinifera L., which is, unfortunately, the only species extensively used in the global wine industry [1]. P. viticola infects all green parts of the vine [2], leaves and bunches in particular,

\footnotetext{
*Correspondence: silvia.toffolatti@unimi.it

Dipartimento di Scienze Agrarie e Ambientali - Produzione, Territorio, Agroenergia (DiSAA), Università degli Studi di Milano, via Celoria 2, 20133, Milan, Italy
}

\section{Biomed Central

penetrating through stomata and extensively forming an intercellular mycelium with haustoria in the mesophyll cells [3]. In favourable climatic conditions, the pathogen causes numerous infection cycles, which are responsible for both quantitative and qualitative yield reductions. Since agricultural practices are almost ineffective in reducing disease incidence [4], chemical control is, at the moment, the most efficient mean to prevent severe downy mildew epidemics [5] and obtain good quality grapes.

Damages due to $P$. viticola could be reduced by using less susceptible grapevine varieties obtained by crossing $V$. vinifera with resistant species and in particular with 
American Vitaceae co-evolved with the pathogen such as V. labrusca L., V. aestivalis Michx., V. rupestris Scheele and $V$. riparia Michx. [6]. The resulting hybrids, however, are often unsuitable for the production of high quality wines due to their unpleasant flavours and aromas.

Both monogenic and polygenic resistance to $P$. viticola have been described in the Vitaceae family $[7,8]$. More recently, single quantitative trait loci (QTL) have been associated with resistance to $P$. viticola in $V$. amurensis Ruprecht [9], V. riparia [10] and in V. vinifera cv Regent [11]. Monogenic resistance is determined by a single dominant gene and has been associated with an hypersensitive response causing stomatal death at the point of infection and was found in the genera Tetrastigma and Cissus [7], whereas polygenic resistance induces a reduction of the pathogen growth after infection and is polygenically determined. The resistance imposed by a single gene is usually easily circumvented by pathogens characterized by a great evolutionary potential [12] such as $P$. viticola which has a high asexual sporulation efficiency, a polycyclic behaviour and sexual reproduction through the formation of oospores. However, also in polygenic resistance, that leads to a disease reduction rather than the absence of disease, host genotypes can respond differently to different pathogen strains [13] upon pathogen adaptation [14]. In the coevolutionary arms race between host and pathogen, the pathogen possesses the advantage of relatively short generation times and higher abundance in number compared to the host [15]. As a consequence, the pathogen can overcome the host defence mechanisms.

The variety Bianca, achieved by crossing the susceptible $V$. vinifera cv Bouvier with the resistant interspecific hybrid Villard Blanc [16], is together with Regent and Solaris one of the few cultivated hybrids resistant to $P$. viticola. Due to the multiple crosses involved in the breeding program, the genetic background of Bianca is mainly composed by $V$. vinifera $(78.09 \%)$, and also by the Northern American species $V$. rupestris (14.58\%), $V$. berlandieri Planch. (3.13\%), V. lincecumii Buckl. (2.64\%) and V. labrusca (1.56\%) [17]. Recently, QTL mapping showed that resistance in $\mathrm{cv}$ Bianca is controlled by a single dominant allele at the Rpv3 locus on chr18, that explains most of the phenotypic variance in downy mildew resistance [18]. The resistance phenotypic traits observed in Bianca are localized necrosis and reduction of the colonization extent and sporulation capacity of $P$. viticola. Information on the interactions between $P$. viticola, cv Bianca and its siblings obtained from a cross with Chardonnay mainly derives from experimental inoculations carried out with isolates coming from naturally infected leaves collected in vineyards [18-20]. Since in single leaves different $P$. viticola genotypes can coexist, host reactions can not be attributed to a specific interaction with a pathogen individual. Therefore both the possible range and effectiveness of resistance should be ascertained only by using single spore isolates, i.e. distinct pathogen genotypes, and by quantitatively assessing disease parameters such as the area under disease progress curve (AUDPC). Host responses to individual $P$. viticola genotypes provide not only a profile of resistance but also insights on the evolutionary potential of the pathogen strains through the investigation of their virulence, defined as degree of damage caused to the host [21], and their fitness i.e.their ability of surviving and reproducing [22]. A rapid increase of genotypes characterized by the ability to breakdown monogenic/ polygenic resistance, as already assessed on cv Bianca in Czech Republic where it is cultivated on a limited acreage [19], affects both effectiveness and durability of resistance [13].

Detailed investigations carried out on various hostpathogen binomials pointed out that resistance reactions to biotrophic fungal infections depend on the activation of several defence mechanisms, including the production of antimicrobial metabolites and proteins (pathogenesis related proteins, PRs) and, at the cell wall level, thickenings, callose appositions in the paramural space and accumulation of phenolic compounds and reactive oxygen species $[23,24]$. While defence reactions against $P$. viticola have been investigated at the morphological and histochemical level mainly on resistant species and only on two resistant hybrids, Solaris [25] and Seyval [26], incomplete information on the resistance mechanisms and on their histochemical features are available on cv Bianca and its siblings. Moreover, since the pathogen colonization pattern and the host histochemical reactions have often been independently examined, it is not clear if the observed structural or histochemical changes in the grapevine tissues are actually associated with the pathogen presence.

The aims of the present work are: (i) to quantitatively evaluate the phenotypic responses of both the parental and the hybrid lines obtained by crossing the susceptible cv 'Chardonnay'x'Bianca' to 5 P. viticola strains each of which derived from a single oospore and assess both the host resistance level and the virulence of the pathogen isolates; (ii) to estimate the fitness of the most virulent isolate of P. viticola; (iii) to characterize at different infection stages the histochemical reactions of the host plants associated with the colonizing structures of the most virulent strain of $P$. viticola.

\section{Results and discussion}

\section{Evaluation of the disease severity}

The first sporangia differentiated by $P$. viticola were generally observed 5-6 days after inoculation. The percentage of sporulating leaf discs did not show great variations, being in most of the cases higher than 50\%, whereas variable 
values of PSA, ranging from 0 to $69 \%$, characterized the different grapevine lines inoculated with $P$. viticola strains (data not shown).

\section{Comparison among strains}

Since significant interactions were found among isolates and $\mathrm{cv} /$ hybrids (Table 1), strain virulence was estimated on each cv/hybrid individually. Except for Chardonnay and the hybrids 18017, 18036 and 18096 (df 4, 10; F $\langle 2.6$; $P\rangle$ $0.05)$, AUDPC (Table 2 ) significantly varied among the isolates on the different hybrids ( $\mathrm{df} 4,10 ; \mathrm{F}>3.7 ; P<0.05)$. In general, $G$ was the most virulent isolate (mean AUDPC 106.2), followed by BAI (78.1), MIX (69.6) and C (62.7), whereas SO showed lower virulence (37.3).

\section{Comparison among cv/hybrid lines}

Considering each $P$. viticola strain, significant differences (df 16, 34; $4.3<\mathrm{F}<9.7 ; P=0.000$ ) among the AUDPC values observed on the different cv/hybrids have been found (Table 2). Based on statistical analysis, host plants have been classified in three different phenotypes: resistant, characterized by low AUDPC; susceptible, with high AUDPC; and intermediate, with AUDPC values not significantly different from the previous ones. For example, following the inoculation with BAI isolate, the parental hybrid Bianca and two offsprings (18036 and 18120) showed a resistant behaviour, 6 offprings (18006, 18017, 18048, 18090, 18100 and 18106) were susceptible, and the remaining ones intermediate (Table 2). As shown in Table 2, the classification of the host plants varied depending on the inoculated strain: for instance, hybrid 18001 was susceptible to strain G, resistant to SO and C and intermediate with BAI and M. Interestingly, the two parents, Chardonnay and Bianca, showed clearly distinct phenotypes, susceptible and resistant, when inoculated with BAI and SO isolates, and an analogous intermediate behaviour when challenged with the remaining three strains. Therefore, among the five isolates tested, three strains induced similar AUDPC in both parental lines showing that resistance mechanisms present in Bianca were not effective in limiting their growth. Overall, Chardonnay and 5 offsprings (18006, 18017, 18048, 18053 and 18088) can be considered intermediate-susceptible, Bianca and 5 offsprings (18036, 18096, 18099, 18103 and 18120) intermediate-resistant, while the remaining hybrids (18001, 18090, 18100, 18106 and 18110) show a variable phenotype (susceptible, resistant or intermediate) depending on the pathogen isolate used for the inoculation.

The significant host/pathogen interaction suggests that different host phenotypes correspond to different pathogen genotypes. However, in most of the cases the plants showed an intermediate-susceptible or intermediateresistant phenotype. The most interesting hybrid found in this study, 18120, resulted resistant to three strains, BAI, $C$ and $\mathrm{M}$, and intermediate to the most and the least virulent strains, $\mathrm{G}$ and SO. However, once the resistant $\mathrm{Cv}$ is cultivated, strains able to colonize resistant grapevine accessions could cause severe damages only if they are characterized by high fitness levels.

\section{Pathogen fitness}

According to Kruskal-Wallis test, the fitness components of the most virulent $P$. viticola strain (G) varied among the different grapevine lines (df:16; H 37.51, sig. 0.02 for $\mathrm{T}_{10} ; \mathrm{H}$ 36.51, sig. 0.02 for MGR; $\mathrm{H}$ 34.36, sig. 0.005 for IEI; H 42.85, sig. 0.000 for SPOR). About 30\% of the grapevine lines considered in this study induced low values of the fitness parameters considered, 30\% high values and the remaining ones an intermediate behaviour (Table 3). In the considered experimental conditions, $10 \%$ of the leaf was covered by sporangia in about 6-7 days, the maximum absolute rate of disease increase occurred two days later and infection efficiency, estimated 10 days after inoculation, was about 0.5. Apart from SPOR, that was particularly high and associated with a wide infected area, the fitness of $P$. viticola on $\mathrm{CV}$ Chardonnay was generally intermediate. The highest PF, associated with particularly low $\mathrm{T}_{10}$ and MGR and high IEI, was found on the hybrids 18001 and 18088. On the resistant parental Bianca, the pathogen was characterized by low $\mathrm{T}_{10}$, MGR and high IEI, therefore by a rapid and widespread colonization of the tissues, but reduced SPOR and, as a consequence, the pathogen showed an intermediate PF. As indicated by $\mathrm{T}_{10}$ and MGR, which

Table 1 Two-factors ANOVA for disease symptoms expressed as AUDPC

\begin{tabular}{|c|c|c|c|c|c|}
\hline Variable & Type III sum of squares & df & Mean sum of squares & $\mathrm{F}$ & Sig. \\
\hline$\overline{\text { Model }}$ & 648397.3 & 84 & 7719.0 & 6.11 & $1.07 \times 10^{-23}$ \\
\hline Intercept & 1277882.8 & 1 & 1277882.8 & 1011.63 & $1.76 \times 10^{-73}$ \\
\hline cv/hybrid & 212910.0 & 16 & 13306.9 & 10.53 & $2.69 \times 10^{-18}$ \\
\hline Isolate & 127372.1 & 4 & 31843.0 & 25.21 & $2.1 \times 10^{-16}$ \\
\hline cv/hybrid $\mathrm{x}$ isolate & 308115.2 & 64 & 4814.3 & 3.81 & $2.09 \times 10^{-12}$ \\
\hline Error & 214743.1 & 170 & 1263.2 & & \\
\hline Total & 2141023.2 & 255 & & & \\
\hline
\end{tabular}


Table 2 AUDPC values and derived phenotype (P) of different cv/hybrids inoculated with each $P$. viticola strain

\begin{tabular}{|c|c|c|c|c|c|c|c|c|c|c|c|}
\hline \multirow[t]{2}{*}{ cv/hybrid } & BAI & \multirow[b]{2}{*}{$\mathbf{P}$} & \multirow{2}{*}{$\frac{\text { SO }}{\text { AUDPC }}$} & \multirow[b]{2}{*}{$P$} & \multirow{2}{*}{$\frac{C}{A U D P C}$} & \multirow[b]{2}{*}{$\mathbf{P}$} & \multirow{2}{*}{$\frac{G}{\text { AUDPC }}$} & \multirow[b]{2}{*}{$\mathbf{P}$} & \multirow{2}{*}{$\frac{M}{A U D P C}$} & \multirow[b]{2}{*}{$\mathbf{P}$} & \multirow{2}{*}{$\frac{\text { Overall }}{\text { phenotype }}$} \\
\hline & AUDPC & & & & & & & & & & \\
\hline Chardonnay & $106.5 \mathrm{cdef}$ & 1 & $85.7 \mathrm{~cd}$ & $\mathrm{~S}$ & $46.4 \mathrm{abc}$ & 1 & $80.3 \mathrm{abcd}$ & 1 & 66.1 abcde & 1 & IS \\
\hline Bianca & $7.7 \mathrm{a}$ & $\mathrm{R}$ & $1.8 \mathrm{ab}$ & $\mathrm{R}$ & $50.0 \mathrm{abc}$ & I & 108.9 abcdef & I & 71.4 abcde & I & $\mathbb{R}$ \\
\hline 18001 & $32.8 \mathrm{bcd}$ & I & $1.8 \mathrm{ab}$ & $\mathrm{R}$ & $0 \mathrm{a}$ & $\mathrm{R}$ & 184.5 ef & $S$ & 83.9 abcdef & 1 & V \\
\hline 18006 & 119.0 def & $\mathrm{S}$ & $42.9 \mathrm{abcd}$ & I & $75 a b c$ & I & 156.6 def & $\mathrm{S}$ & $36.3 \mathrm{abc}$ & 1 & IS \\
\hline 18017 & 112.5 ef & $S$ & $48.2 \mathrm{abcd}$ & 1 & $85.7 \mathrm{abcd}$ & 1 & 114.9 abcdef & 1 & 73.8 abcde & 1 & IS \\
\hline 18036 & $10.7 \mathrm{ab}$ & $\mathrm{R}$ & $55.4 \mathrm{abcd}$ & I & $50.0 \mathrm{abc}$ & I & $47.0 \mathrm{ab}$ & $\mathrm{R}$ & 48.8 abcde & I & $\mathbb{R}$ \\
\hline 18048 & $191.1 \mathrm{f}$ & $S$ & $44.7 \mathrm{abcd}$ & I & $151.8 \mathrm{~cd}$ & $S$ & 154.2 cdef & I & 134.5 def & $S$ & IS \\
\hline 18053 & 83.3 cdef & I & $123.2 \mathrm{~d}$ & $\mathrm{~S}$ & $69.6 \mathrm{abc}$ & I & 108.9 abcdef & I & $31.0 \mathrm{abc}$ & 1 & IS \\
\hline 18088 & $53.0 \mathrm{cdef}$ & I & 60.7 bcd & I & $71.4 a b c$ & I & $187.5 \mathrm{f}$ & $S$ & $181.6 \mathrm{f}$ & $S$ & IS \\
\hline 18090 & 119.6 ef & $\mathrm{S}$ & $0 \mathrm{a}$ & $\mathrm{R}$ & $100 \mathrm{bcd}$ & I & 142.9 bcdef & 1 & $35.7 \mathrm{abc}$ & 1 & V \\
\hline 18096 & 70.2 cdef & I & $12.5 \mathrm{abc}$ & I & $8.9 a b$ & $\mathrm{R}$ & $46.4 \mathrm{a}$ & $\mathrm{R}$ & $38.7 \mathrm{abcd}$ & 1 & $\mathbb{R}$ \\
\hline 18099 & 38.7 bcde & I & $48.2 \mathrm{abcd}$ & I & $73.2 \mathrm{abc}$ & I & $57.7 \mathrm{abc}$ & $\mathrm{R}$ & $1.2 \mathrm{ab}$ & $\mathrm{R}$ & $\mathbb{R}$ \\
\hline 18100 & 114.9 ef & $\mathrm{S}$ & $48.2 \mathrm{abcd}$ & I & $55.4 \mathrm{abc}$ & I & $42.9 \mathrm{a}$ & $\mathrm{R}$ & 108.9 bcdef & 1 & V \\
\hline 18103 & 51.2 cdef & I & $46.4 \mathrm{abcd}$ & I & $50 a b c$ & I & 95.2 abcde & 1 & $3.6 \mathrm{ab}$ & $\mathrm{R}$ & $\mathbb{R}$ \\
\hline 18106 & 106.6 def & $\mathrm{S}$ & $10.7 \mathrm{abc}$ & 1 & $10.7 \mathrm{ab}$ & $\mathrm{R}$ & 90.5 abcde & I & 117.8 cdef & $\mathrm{S}$ & V \\
\hline 18110 & 81.0 cdef & I & $0 \mathrm{a}$ & $\mathrm{R}$ & $167.9 \mathrm{~d}$ & $S$ & 122.6 abcdef & I & 150.6 ef & $S$ & V \\
\hline 18120 & $28.5 b c$ & $\mathrm{R}$ & $3.6 \mathrm{abc}$ & I & $0 \mathrm{a}$ & $\mathrm{R}$ & $64.9 \mathrm{abcd}$ & I & $0 \mathrm{a}$ & $\mathrm{R}$ & $\mathbb{R}$ \\
\hline
\end{tabular}

Based on the results of ANOVA and multiple comparison of the means, the plant individual phenotypes are classified as susceptible (S), intermediate (I) or resistant (R). Overall phenotypes of each cv/hybrid are intermediate-susceptible (IS), intermediate-resistant (IR) or variable (V). Mean values within the same column followed by the same letter are not significantly different at the $P=0.05$ level of probability.

Table 3 Estimated components of fitness and composite fitness index of strain G on each cv/hybrid

\begin{tabular}{|c|c|c|c|c|c|}
\hline cv/hybrid & $T_{10}$ & MGR & IEI & SPOR & $\mathrm{PF}$ \\
\hline Chardonnay & 170.58 abcdefg & 9.20 abcdefg & 0.49 abcde & $12.05 \mathrm{ghi}$ & 3.80 abcdefg \\
\hline Bianca & $143.65 a b c$ & $8.63 a b c$ & 0.53 cde & $10.13 \mathrm{abcd}$ & 4.98 cdefg \\
\hline 18001 & $123.19 \mathrm{a}$ & $7.09 \mathrm{a}$ & $0.75 \mathrm{e}$ & 11.12 defg & $9.63 \mathrm{~g}$ \\
\hline 18006 & $132.89 a b$ & 8.70 abcde & 0.50 bcde & $9.91 \mathrm{abc}$ & 4.40 defg \\
\hline 18017 & $145.20 \mathrm{abcd}$ & 8.72 abcdef & 0.51 cde & $9.83 a b$ & 4.11 bcdefg \\
\hline 18036 & 183.17 cdefg & $12.51 \mathrm{defg}$ & $0.27 a b c$ & 11.25 defgh & $1.03 \mathrm{abcd}$ \\
\hline 18048 & $131.72 a b$ & $8.65 \mathrm{abcd}$ & 0.49 abcde & 10.88 abcdef & $4.93 \mathrm{efg}$ \\
\hline 18053 & 177.97 bcdefg & $12.74 \mathrm{efg}$ & $0.23 a b$ & 10.94 bcdef & 1.20 abcde \\
\hline 18088 & $102.66 \mathrm{a}$ & $6.85 a b$ & $0.68 \mathrm{de}$ & 10.96 cdef & $16.57 \mathrm{~g}$ \\
\hline 18090 & 149.80 abcde & $8.35 a b c$ & $0.64 \mathrm{de}$ & 11.31 efgh & $6.77 \mathrm{fg}$ \\
\hline 18096 & $301.98 \mathrm{~g}$ & $22.67 \mathrm{~g}$ & $0.16 a$ & $9.93 \mathrm{ab}$ & $0.33 \mathrm{a}$ \\
\hline 18099 & 193.15 defg & 11.38 bcdefg & $0.26 \mathrm{abcd}$ & 10.26 abcde & 1.34 abcdef \\
\hline 18100 & $211.01 \mathrm{efg}$ & $13.39 \mathrm{fg}$ & $0.24 a b c$ & $9.09 \mathrm{a}$ & $0.66 a b c$ \\
\hline 18103 & 187.59 cdefg & 12.02 cdefg & 0.27 abcde & $12.04 \mathrm{hi}$ & 1.86 abcdefg \\
\hline 18106 & 190.09 cdefg & 12.12 abcdefg & 0.32 abcde & $13.93 \mathrm{i}$ & 2.69 abcdefg \\
\hline 18110 & 154.76 abcdef & $8.46 a b c$ & $0.61 \mathrm{de}$ & 11.34 efghi & $5.75 \mathrm{fg}$ \\
\hline 18120 & $231.02 \mathrm{fg}$ & $15.67 \mathrm{~g}$ & $0.12 \mathrm{a}$ & $12.05 \mathrm{fghi}$ & $0.46 \mathrm{ab}$ \\
\hline
\end{tabular}

The individual fitness components are $\mathrm{T}_{10}, \mathrm{MGR}$, IEl and SPOR, the composite index is PF. Mean values within the same column followed by the same letter are not significantly different at $P=0.05$ level of probability. 
are estimates of the time required for disease severity to reach $10 \%$ and the inflection point respectively, the growth of the pathogen was slower on 18096, 18100 and 18120. On these lines IEI was moreover restricted, but while the number of sporangia differentiated per unit of infected area was reduced on 18096, significantly higher values of SPOR, analogous to those of the susceptible parental line Chardonnay, were detected on 18120. No differences were observed in the germination rates of sporangia differentiated in the different Vitis genotypes.

The most virulent strain, G, showed an analogous composite fitness index on the susceptible and resistant parental cv, Chardonnay and Bianca. Since fitness can be defined as the combined ability of an organism to survive and reproduce, it seems likely that no costs to the pathogen are associated with its capacity to overcome the host resistance mechanism. Despite the absence of significant differences in the composite fitness index, it must be pointed out that in absolute terms on cv Chardonnay and in general on the IS hybrids, the pathogen more extensively colonized the tissues and differentiated an higher number of sporangia than on cv Bianca and other IR hybrids, such as 18120.

\section{Histological analyses \\ Colonization pattern}

Encysted and germinating zoospores were observed in proximity of the stomata 24 hours after inoculation on all the examined grapevine lines. In most of the cases the substomatal vesicle, originating from the infection peg, was visible (Figure 1b), whereas just in a few infected stomata the primary hyphae with the first haustorium were also recognizable (Figure 1a). In some cases (18103 and 18110), callose depositions were observed on the cells surrounding the substomatal cavity immediately underneath the germinating zoospore (Figure 1c). At 2 dai, the primary hypha with haustoria, recognizable from the brightly fluorescent neck covered by callose, started branching inside the leaf tissues of all the plants except for 18096 and 18106 (Figure 1d-f). However, some differences in the pathogen structures could be detected. Due to the great variability observed in the length of the primary hypha, the different cv/hybrids could be divided into three groups: the first characterized by high values, ranging between 100-200 $\mu \mathrm{m}$, of the pathogen vegetative structures, the second by an intermediate range $(45-100 \mu \mathrm{m})$ and the third by low values $(44-19 \mu \mathrm{m})$. Members of the different resistant classes could be found in each group (Figure 2). For example, the first group includes 18048, 18088 (IS), 18036, 18103 (IR), 18100 and $18110(\mathrm{~V})$, while the second contains the parental cultivars and 18006, 18017 (IS), 18120 (IR) and 18001 (V) and the third 18053 (IS), 18099 (IR) and 18090 (V). Due to the extensive growth inside the tissues of some grapevine plants, the hyphal growth could not be measured from 3 dai onwards. The hyphal diameter ranged between 5 and 10 $\mu \mathrm{m}$ on most of the investigated cv/hybrids except for a few cases including the IR Bianca at 2 and 3 dai ( 3 and $1.8 \mu \mathrm{m}$ ), 18120 at 2 dai $(2.7 \mu \mathrm{m})$ and 18096 at 3 dai $(3.1 \mu \mathrm{m})$ and the $\mathrm{V} 18090$ at 2 dai $(2.7 \mu \mathrm{m})$.

At 3 dai the differences between susceptible and resistant plants were clearly visible. While in the first case $P$. viticola started spreading inside the infected tissues and was mainly limited by the leaf veins (Figure $1 \mathrm{~g}$ ), in the resistant individuals the mycelium growth was restricted to the area close to the penetration stoma (Figure 1h) and in some cases brightly fluorescent appositions of callose were observed around the hyphae (Figure 1i,o) and in the surrounding stomata (Figure 3d). At 4 dai, the mycelium diffusion inside the susceptible individuals almost completely covered the infected area (Figure 1j), while on the resistant ones the pathogen growth was still restricted (Figure 1k) and degenerated hyphae were visible near the penetration point. However, close to the collapsed pathogen structures, it was still possible to observe some normal hyphae characterized by regular diameters (Figure 11). At 7 dai the mycelium growth increased (Figure 1n) and sporulation occurred (Figure $1 \mathrm{~m}$ ) in all the samples even if at a variable rate.

The amount of $P$. viticola DNA inside each of the 12 inoculated leaf discs was estimated quantitatively by realtime PCR (calibration curve: $y=-3.4 x+25.4 ; r^{2}=0.996$; PCR efficiency $=0.97$ ). The average DNA amount ranged between 20-70 ng/leaf discs in most of the samples apart from Bianca, 18001, 18036, 18103, 18110, 18120, showing lower values (0.5-14.2 ng), and 18099, characterized by a higher value (117 ng) (Figure 4). A positive linear correlation was found among the amount of $P$. viticola DNA, the dimension of the infected areas and the number of sporangia differentiated by the pathogen on the susceptible parental line Chardonnay, suggesting that a high hyphal density and an abundant sporulation correspond to an extensive mycelium colonization (Table 4). A positive correlation between the dimension of the infected areas and sporulation was also found on the resistant cv Bianca. However, a negative correlation characterized the amount of $P$. viticola DNA and both dimension of the colonized areas and amount of sporangia, suggesting that in this case growth and sporulation are associated with a low hyphal density. In most of the hybrids examined, no significant correlation was found among the parameters except for 18036 (DNAinfected areas), 18053 (DNA-sporangia) and 18106 (infected areas-sporangia).

\section{Peroxidase activity}

Grapevine peroxidases belonging to class III group and located in cell walls or vacuoles, catalyze the oxidation of a broad range of substrates, such as the cell wall protein extensin, plant growth regulators and in particular the auxin indole-3-acetic acid (IAA), and phenolics 




(benzoic acids, stilbenes, flavonols, cinnamyl alcohols and anthocyanins) reducing $\mathrm{H}_{2} \mathrm{O}_{2}$ [27]. In plantpathogen interactions, peroxidases play a role in cell wall rigidity, through a cross-linking activity on phenolic monomers that leads to the formation of suberin and the oxidative coupling of lignin subunits, and, through the hydroxylic cycle, contribute to the oxidative burst producing reactive oxygen species (ROS) that are 

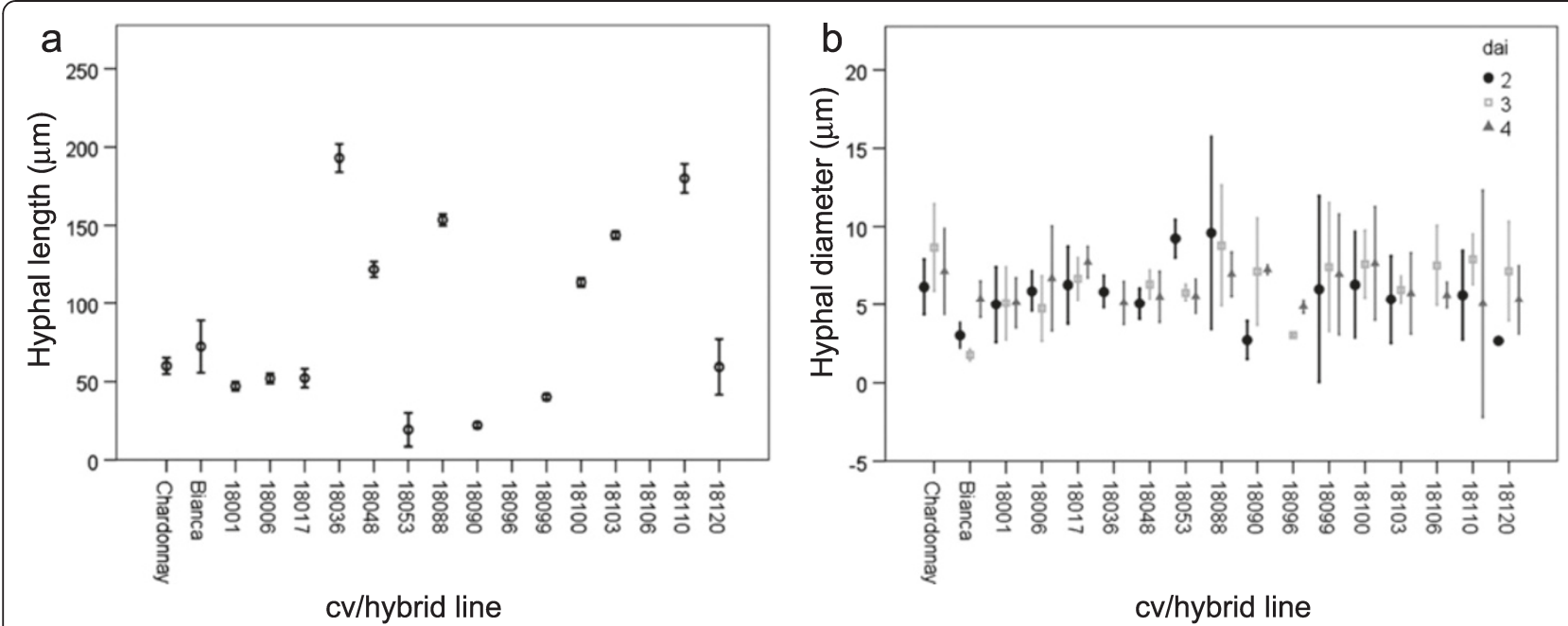

Figure 2 Early development of $P$. viticola inside the leaf tissues. Hyphal length (a) and diameter (b) measured at 2 and $2-4$ dai respectively. Bars represent confidence interval (95\%).

involved in the hypersensitive response and more generally in cell death [28].

Peroxidase activity (POX) in both inoculated and not inoculated leaves was evaluated qualitatively by transmission light microscopy, and quantitatively by spectrophotometry, exploiting the chromogenic property of TMB that undergoes a change in colour upon oxidation by peroxidase in presence of hydroperoxide $[29,30]$.

The spectrophotometric assay indicates that, compared to the susceptible Chardonnay and the other samples tested, the resistant individuals Bianca and 18120 are characterized by a higher basal POX (Figure 5).

Wilcoxon signed-rank test showed a significant increase in POX followed the inoculation with $P$. viticola in only $38 \%$ of the cases (Table 5). Just in 4 samples (18088, 18110, 18106 and 18120) the increase in POX occurred between 1-2 dai. While in the first three cases $(18088,18110,18106)$ it ranged between 0.005 and 0.014 and no significant reduction in the host colonization was observed, in the resistant hybrid 18120 the increase was more consistent (0.154) and associated with a reduced colonization of the tissues. In the other samples, including Chardonnay and Bianca, the increase occurred between 3 and 6 dai, when the pathogen was already diffusing inside the leaf tissues and differentiating the first sporangiophores. A generalised increase of POX was also detected at 4-5 dai in both resistant and suceptible genotypes by Kortekamp and Zyprian [26]. The resistant individuals Bianca and 18120 showed an higher basal POX than susceptible plants, as in the case of the resistant $V$. riparia selections Gloire de Montpellier and Lake St. George and the interspecific hybrid Seyval [26]. In these selections, the infection caused an increased production of ROS, hypersensitive response and POX in cells flanking the infection point. Apart from 18120, the early increase in POX activity was not associated with the host phenotype.

Microscopic observations showed the occurrence of POX in all the host genotypes on the guard cell walls and vacuoles of the stomata close to the areas infected by $P$. viticola both in the early phases of the infection process, at 1-3 dai, and in the later stages corresponding to the sporangiophore differentiation, at 4-6 dai (Figure 3a,c and g). Traces of POX were also visible at the base of the sporangiophore, a structure in close contact with the stoma (Figure 3h). The susceptible cv Chardonnay did not show any blue staining inside the stomata before the beginning of sporulation (4 dai). POX, localized on both stomata and cell walls, was always associated with browning of the host cells (Figure 3c) and in the resistant individuals Bianca and 18120, with altered pathogen structures. However, it did not completely prevent the colonization of the host tissues by $P$. viticola, that was in most of the cases able to grow and sporulate (Figure $3 \mathrm{~b}, \mathrm{f}$ and $\mathrm{h}$ ) even if over a reduced area. For example, 3 days after inoculation on $\mathrm{cv}$ Bianca POX was observed in the plasma membrane of the epidermal cells surrounding a stoma showing brown cells underneath (Figure 3c). In the area immediately under the stoma, aniline blue staining revealed an altered structure of $P$. viticola mycelium, surrounded by callose depositions and with no recognizable haustoria (Figure $3 \mathrm{~d} \mathrm{~m}_{1}$ ). However, the pathogen differentiated a normal branching mycelium and haustoria with the callose neck clearly visible (Figure $3 \mathrm{~d} \mathrm{~m}_{2}$ ) in the surrounding tissues. The synthesis of ROS by NADPH oxidases, balanced by detoxification systems able to maintain redox homeostasis, during different growth and reproduction phases such as hyphal growth, sporulation and spore differentiation and germination is a 

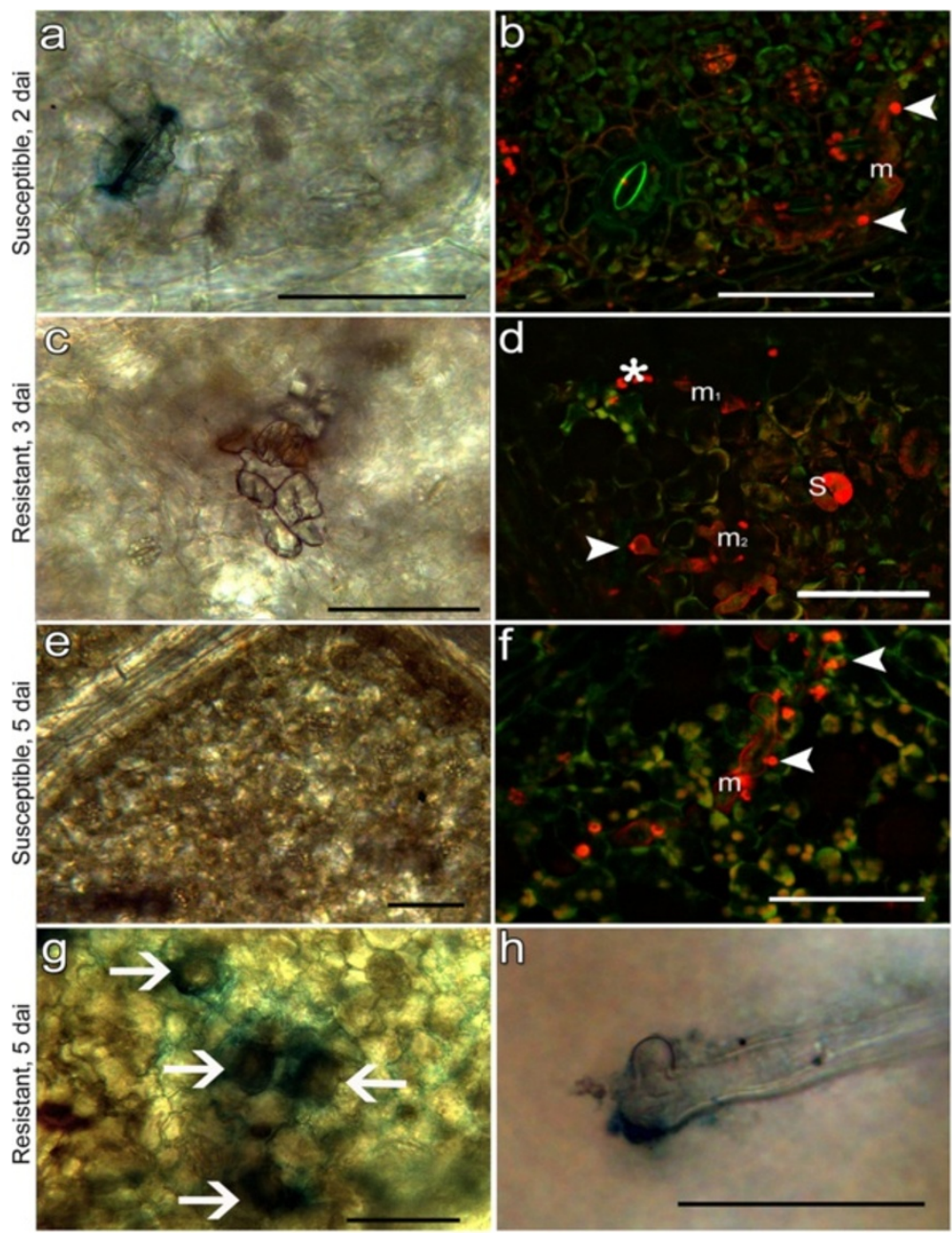

Figure 3 Localization of peroxidase acitivity in infected leaf tissues. POX (blue) have been visualized by transmission light microscopy following TMB staining ( $a, c, e, g, h)$. The corresponding P. viticola vegetative structures (red) inside the leaf tissues (green) have been visualized in epifluorescence after aniline blue staining (b, d, f). (a) Stoma of the susceptible hybrid 18048 showing POX at 2 dai. (b) P. viticola mycelium (m) with haustoria (arrowhead) close to the stoma visualized in (a). Autofluorescent red chloroplasts inside the stomata are visible. The picture was obtained by overlapping a surface section (epidermal cells) and a lower section (mesophyll). (c) Epidermal cells of the resistant cv Bianca showing POX on the plasma membrane, that is detached from the wall, and browning under the stoma at 3 dai. (d) Lower section of (c) showing an altered mycelium $\left(m_{1}\right)$ intensely coloured, probably due to callose deposition (asterisk), and no haustoria immediately under the browning area and regular vegetative structures of the pathogen $\left(\mathrm{m}_{2}\right)$ in a surrounding area showing no peroxidase activity. Asterisk indicates callose, $\mathbf{S}$ callose in a closed stoma. (e) Leaf tissues of cv 18048 lacking POX at 5 dai. (f) Regular mycelium (m) with haustoria (arrowheads) in the same area. (g) POX in the epidermal walls of the cells surrounding the stomata with sporangiophores (arrows). Hybrid 18100, 5 dai. (h) Detail of a sporangiophore with POX at the exit point. Scale bar $=50 \mu \mathrm{m}$.

common feature in fungi [31]. Since the sporangia were viable, the presence of POX could be related to the differentiation of the zoospores, whereas in the case of sporangiophores, since POX is mainly located inside fungal structures in close contact with the stomata, it could be more likely a response to the oxidative stress of the host leading to the necessity of maintaining the redox balance.

\section{Callose}

Callose deposition localised in the stomata, the spongy cells and around the advancing hyphae (Figures 1c,0; 3d; 6h) was the first structural response detectable in the infected tissues of cr Bianca and its siblings from 1 dai onwards. In Chardonnay, callose was limited to some stomata and detected in later phases, starting from 5 dai. Callose contributes to the penetration resistance against some agents of 


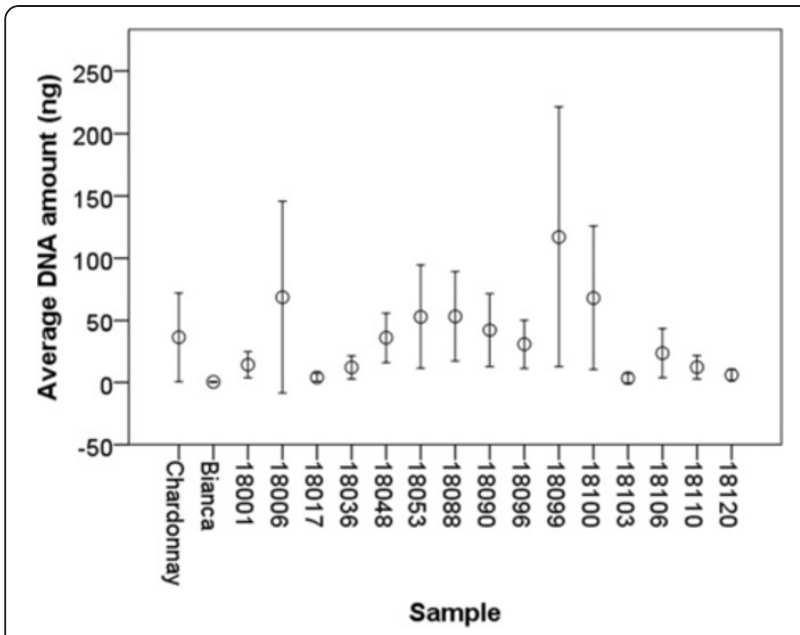

Figure 4 Average $P$. viticola DNA amount (ng) in the leaf discs. Bars represent confidence interval (95\%).

powdery mildew [32] and it is involved in the restriction of bacterial colonization. Callose does not seem to play an important role in limiting the development of $P$. viticola in other tolerant or resistant Vitis cultivars, since it is not detected until 5 dai [25,33]. In Bianca and its hybrids, on the contrary, callose deposition at the penetration points occurrs rapidly and is usually followed by the encasement of the developing hyphae and the penetrating haustoria. Callose plugging of the stomata represents a physical barrier to both the penetration and evasion of the pathogen and could be related to the reduction of sporangial amount produced in some resistant genotypes. In the host cells callose can hamper the nutrient exchange mediated by the haustorium, while its deposition around the hyphae efficiently contributes to delay or block the pathogen colonization of the host [34].

Table 4 Correlation among DNA amount, infected area and number of sporangia

\begin{tabular}{lccc}
\hline Cv/hybrid & Variable & Infected area & Sporangia \\
\hline Chardonnay & DNA & $0.55(0.07)$ & $0.700(0.01)$ \\
& Infected area & 1 & $0.721(0.01)$ \\
Bianca & DNA & $-0.811(0.001)$ & $-0.748(0.005)$ \\
& Infected area & 1 & $0.723(0.008)$ \\
18036 & DNA & $0.664(0.018)$ & - \\
18053 & Infected area & 1 & - \\
& DNA & - & $0.599(0.04)$ \\
& Infected area & 1 & -
\end{tabular}

Spearman's rho correlation coefficients for DNA amount (ng), dimension of infected areas $\left(\mathrm{mm}^{2}\right)$ and number of sporangia differentiated and level of significance (parenthesis). ' - ' Indicates no significant correlation among the variables.
Table 5 POX $(\Delta \mathrm{E})$ of the samples inoculated with $P$. viticola from 1 to 6 dai

\begin{tabular}{lcccccc}
\hline cv/hybrid line & $\mathbf{1}$ & $\mathbf{2}$ & $\mathbf{3}$ & $\mathbf{4}$ & $\mathbf{5}$ & $\mathbf{6}$ \\
\hline Chardonnay & 0.003 & 0.006 & $0.010^{*}$ & $0.110^{*}$ & 0.025 & 0.006 \\
Bianca & 0.058 & 0.014 & -0.009 & $0.057^{*}$ & -0.044 & $0.056^{*}$ \\
18001 & -0.019 & -0.019 & $0.023^{*}$ & $0.064^{*}$ & -0.020 & 0.016 \\
18017 & $-0.030^{*}$ & 0.045 & 0.008 & 0.017 & $0.012^{*}$ & $0.026^{*}$ \\
18048 & -0.053 & 0.006 & 0.006 & $0.056^{*}$ & -0.018 & -0.023 \\
18088 & $0.005^{*}$ & $-0.017^{*}$ & $0.011^{*}$ & $0.035^{*}$ & $0.012^{*}$ & $-0.009^{*}$ \\
18100 & 0.006 & $-0.017^{*}$ & $0.023^{*}$ & 0.016 & $0.009^{*}$ & $0.009^{*}$ \\
18106 & 0.033 & $0.009^{*}$ & -0.007 & 0.036 & $0.034^{*}$ & $0.009^{*}$ \\
18110 & $0.014^{*}$ & -0.021 & $-0.063^{*}$ & $0.119^{*}$ & $0.033^{*}$ & $-0.029^{*}$ \\
18120 & -0.027 & $0.154^{*}$ & 0.003 & 0.032 & 0.120 & -0.033 \\
\hline
\end{tabular}

*Indicates a significant difference between not inoculated and inoculated samples at $P=0.05$ level of probability.

\section{Phenolic compounds}

Phenolics are ubiquitous compounds in plants that include numerous and diverse compounds that have a role in a large number of functions in growth, development and defence from both abiotic and biotic stresses [35]. They are mainly involved in postinfectional responses to disease agents but they also act as preinfectional barriers $[32,36]$. During the interaction with $P$. viticola the main phenolic compounds detected in different grapevine varieties are stilbenes, flavonoids [37-40] and phenolic compounds oxidized by POXs [41], which are accumulated more rapidly and to a higher extent in resistant genotypes in comparison to V. vinifera. The phenolic compounds detected in the leaves of cv Chardonnay not inoculated with $P$. viticola were mainly located in the leaf veins, whereas in Bianca they were also found in a few stomata (data not shown). Upon nitrous-acid reaction, phenolic compounds such as catechols and chlorogenic acid develop a dark cherry-red colour. Positive reactions were observed on the leaf veins, epidermis and mesophyll of resistant and susceptible plants inoculated with $P$. viticola at 5 and 7 dai, but while in susceptible tissues phenolics did not interfere with the pathogen colonization (Figure 6a), in resistant samples they concentrated inside the vacuoles of the spongy mesophyll cells immediately underneath the penetration sites (Figure 6c).

Neu's and Wilson's reagents, used for the detection of flavonoids, gave analogous results: no specific reaction to the presence of $P$. viticola was observed in susceptible plant tissues (Figure 6e), whereas the spongy mesophyll cells of the resistant hybrids showed a strong fluorescent signal and a shrinked structure (Figure 6g). Flavonoids were also detected in guard cells and on the walls of the surrounding epidermal cells.

Lignin, a complex polyphenolic compound, is a normal component of the host cell wall, particularly in the 


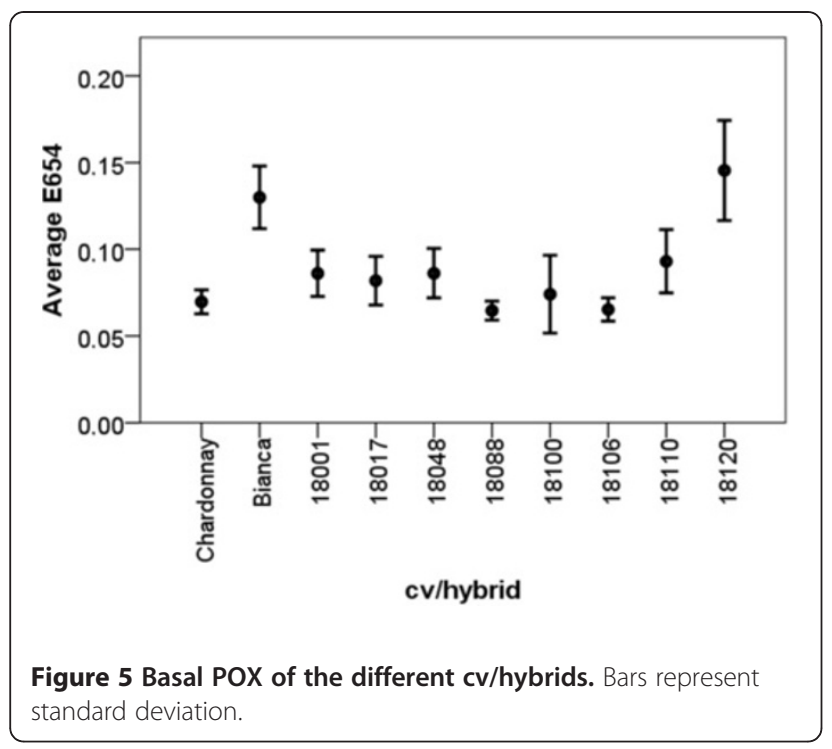

vascular system and can be generated by mechanical wounding or act as a non-degradable, mechanical barrier to fungal pathogens at a preinfectional level or in response to a pathogen attack $[42,43]$. Lignin was observed in both inoculated and not inoculated samples of susceptible and resistant cv/hybrids at 7 and, at higher levels, at 15 dai. It localized in the leaf veins, stomata and walls of the surrounding epidermal cells. No specific reaction associated with the pathogen presence in susceptible plants (Figure 6i,j), whereas in the resistant hybrids a strong reaction to phloroglucinol- $\mathrm{HCl}$ could be found inside some infected stomata (Figure 6k) where the pathogen growth was blocked at the substomatal vesicle level (Figure 61). In the leaf tissues of the susceptible plants where phenolic compounds have been detected, the pathogen mycelium showed regular structures and a large diffusion (Figure $6 \mathrm{~b}, \mathrm{f}, \mathrm{j}$ ). In resistant hybrids, despite the high presence of sporangia and germinating zoospores (Figure 6d), the pathogen was not




always able to colonize the tissues, since its development was either blocked at the substomatal vesicle level (Figure 6l) or it was limited to the areas close to the penetration site (Figure $6 \mathrm{~h}$ ).

\section{Conclusions}

Durability i.e. the maintenance of an adequate level of resistance throughout the useful lifetime expected from a variety [22] is one of the most important objectives of plant breeding programmes for resistance. Useful lifetime is usually short for annual crops which can be easily replaced, but it could last several years in perennial cultivated plants, which are very costly to replace or to protect by other means against virulent pathogens. Resistant annual crops are often characterized by the presence of single resistance genes (qualitative resistance), which generally induce a strong selection pressure on the pathogen populations and, as a consequence, a rapid increase in the frequency of strains that are able to overcome the host defence reactions. Quantitative resistance due to multiple genes and resulting in reduced disease incidence is usually more useful for perennial crops, since it assures more durable results, even if adaptation to the host has also been observed in the case of polygenic traits [14]. As already pointed out, resistance to $P$. viticola is associated with the synthesis of physical barriers, such as callose [33] and lignin [37] appositions, and substances with antifungal properties such as pathogenesis-related proteins [44], peroxidases [41] and phenolic compounds $[37,45]$. The host response depends on many factors linked to both the environment and the pathogen. In particular, the pathogen virulence can modulate the host defence responses. Field populations of $P$. viticola that are presumably composed of different genotypes are normally used for the screening for resistance in grapevine $[19,20,46]$, but this method prevents a comparative evaluation of the interaction between different host and pathogen genotypes. To the best of our knowledge, no prior attempt has been made to evaluate grapevine resistance as performed in the present study by combining the use of individual genotypes, isolated from single germinated oospores sampled from geographically distinct vineyards, and the quantitative assessment of the disease intensity. The results clearly show that the disease level expressed as AUDPC is determined not only by the isolate virulence and the host resistance level but also by their interaction. Therefore particularly virulent strains such as $G$ are likely to cause conspicuous damages, at least to the leaf tissues, in hybrids characterized by a resistant behaviour against less aggressive strains. On the other hand, it must be pointed out that less severe epidemics would develop on the resistant hybrids in comparison with the susceptible varieties due to a constant reduction of the sporulation efficiency. The reduction of sporulation efficiency is of paramount importance in the field, since the amount of sporangia produced by $P$. viticola greatly affects the epidemic growth rate of the pathogen. In presence of favourable climatic conditions, in fact, even from a limited number of infection foci the pathogen can potentially spread in the host population thanks to an abundant production of sporangia, leading to severe infections on both leaves and clusters.

Histological investigations confirmed the differences in the interaction between P. viticola strain G and its hosts, particularly evident from 4 dai onwards. In the susceptible individuals, $P$. viticola colonization followed a regular pattern leading to an extensive growth in the host tissues and sporulation. On the contrary, the pathogen development in the resistant plants was characterized by alterations in the hyphal diameter in the early growth phases and a reduced colonization of the tissues. The resistant reactions therefore likely occurr early in the colonization process and seem to limit the pathogen growth instead of completely blocking it.

Colonization patterns in resistant and intemediate genotypes were associated with numerous changes in both the structural and chemical leaf characteristics, due to the activation of complex defense responses which eventually cause the necrotic lesions and the reduced colonization already described in Bianca [18]. A rapid callose deposition at the penetration point and around the developing hyphae seems to characterize the interaction between $P$. viticola and the resistant genotypes. The cytochemical analysis carried out in this study showed that peroxidatic activity and phenolic compounds synthesis are involved in disomogenous defense reactions of the resistant plants. In fact the pathogen colonization is stopped in the necrotic lesions but continues in the nearby tissues where no detectable host reaction occurs. Flavonoids and other phenolics were observed inside the infected stomata and surrounding epidermal cells together with shrinked and brown mesophyll cells in close contact to the developing hypha. No close association between pathogen and phenolics could be detected in the susceptible cv Chardonnay. Therefore the browning content of the cells close to the areas colonized by the pathogen in resistant plants could be the result of the oxidation of flavonoids to semiquinones and quinones, which in turn react with other phenols, amino acids or proteins forming brown products [47]. In healthy cells, the oxidases and their substrates are compartmentalized in different parts (cytoplasm and vacuoles respectively), and come in contact with each other when the cells are in some way damaged [48]. No other structural changes in the infected areas were observed until 7 dai when in the resistant genotypes lignin deposition was detected in the walls of the infected 
stomata and surrounding cells. In all the tested genotypes, lignin has been detected from 1 dai in the leaf veins, but its association with the pathogen occurred only in the resistant varieties in the final infection stages, as already observed by Dai and co-workers [37,49]. Lignin apposition probably represents the final stage of the defence reaction started with POX.

In conclusion, the response of Bianca and its siblings to $P$. viticola varied according to the inoculated strain, which in turn demonstrated different virulence levels. The most virulent strain, without any reduction in its overall fitness, induced the same disease intensity in Chardonnay and Bianca, suggesting that no fitness costs are associated with the resistance breakdown. However some hybrids showed an intermediate resistant phenotype and could be used in further field trials. Resistance is associated with a limitation of the pathogen growth, due to multiple reactions, ranging from callose deposition, POX activity and accumulation of phenolic compounds. From an epidemiological point of view, the reduction of sporangial production, a phenotypic trait common to to $\mathrm{cv}$ Bianca and all its siblings, is particularly interesting and can contribute to a more efficient downy mildew control.

\section{Methods}

\section{Plant material}

Fifteen grapevine hybrids (18001, 18006, 18017, 18036, 18048, 18053, 18088, 18090, 18096, 18099, 18100, 18103, $18106,18110,18120)$ obtained as described in Peterlunger et al. [50] and Bellin et al. [18], by crossing 'Chardonnay', susceptible, and 'Bianca', resistant, were provided by the University of Udine, Italy together with the two parental plants. Two potted plants per individual were cultivated in a screen house at the Faculty of Agriculture of the University of Milan, Italy. Actively growing plants were regularly watered via a drip system and fertilized with the controlled release fertilizer Osmocote Pro (Scotts Professional Italia Srl, Treviso, Italy). Both propagation and experimental inoculations with $P$. viticola were carried out on the $3^{\text {rd }}-4^{\text {th }}$ fully expanded leaf starting from the apex of the shoot. Leaves or leaf discs were placed, lower surface upwards, in Petri dishes (Ø 9 or $6 \mathrm{~cm}$ ) containing WAK medium: 1\% water-agar (Agar Bacto, Oxoid) amended with $2 \mathrm{mg} / \mathrm{L}$ kinetin (6-Furfurylaminopurine, Sigma-Aldrich s.r.l. Italy), to retard leaf senescence [51]. The samples were incubated in a growth chamber at $20 \pm 2^{\circ} \mathrm{C}(16 \mathrm{~h}$ of light per day).

\section{$P$. viticola isolates}

Five $P$. viticola isolates, weekly propagated on detached leaves of cv 'Cabernet franc' plants grown in screen house, were considered in this study. The strains, BAI, $\mathrm{C}, \mathrm{G}, \mathrm{SO}$, and $\mathrm{M}$, were isolated from single germinating oospores differentiated respectively on cv 'Baresana'
(Puglia, southern Italy), cv 'Corvina', cv Merlot (Veneto, north-eastern Italy), cv 'Nebbiolo' and cv 'Pinot gris' (Lombardia, northern Italy).

Grapevine leaves showing mosaic symptoms were sampled in October in order to collect leaf fragments rich in oospores which were overwintered in controlled conditions of temperature and humidity (BAI, C, G and $\mathrm{M})$ or in vineyard (SO) until April. Germination assays were carried out on the oospores isolated from the leaves and incubated for one week on $1 \%$ water-agar (Agar Noble, DIFCO) at $20^{\circ} \mathrm{C}$ [52]. Single germinating oospores with fully developed macrosporangia were transferred with a sterile needle to $10 \mu \mathrm{L}$ water droplets on leaf discs $(\varnothing 1.5 \mathrm{~cm})$ of cv 'Cabernet franc'. At the end of the incubation period, sporangia were propagated on detached leaves as described for the leaf disc assay in the following paragraph.

\section{Experimental inoculations and evaluation of the disease severity}

The experimental inoculations were carried out on three replicates of 4 leaf discs per plant placed on WAK in Petri dishes $(\varnothing 6 \mathrm{~cm}$ ) by uniformly spraying $1 \mathrm{~mL}$ of a sporangial suspension $\left(5 \times 10^{4}\right.$ sporangia/mL) per dish. The disease severity on the samples incubated in growth chamber $\left(20 \pm 2^{\circ} \mathrm{C}, 16 \mathrm{~h}\right.$ light $)$ was evaluated at the stereo microscope (Leica Wild M10) every 24 hours between 4 and 9 days after inoculation (dai). The leaf discs were classified in eight classes (0-7) according to the percent area showing sporulation, where $0=$ absence of sporulation, $1=0.1-2.5 \%, 2=2.5-5 \%, 3=5-10 \%, 4=$ $10-25 \%, 5=25-50 \%, 6=50-75 \%$, and $7=75-100 \%$ of the leaf area covered by sporulation. The percentage of sporulating area (PSA) of each replicate was calculated from the modified formula of Towsend and Heuberger [53] taking into account the sporulation classes: $P S A=$ $\frac{\sum(n \times v)}{7 N} \times 100$ where $n=$ number of leaf discs in each class, $v=$ numerical value of each class and $N=$ total number of leaf discs in the sample. Area under disease progress curve (AUDPC) was calculated [54,55] from PSA values in order to evaluate the host phenotype and virulence of $P$. viticola strains. AUDPC was chosen because it summarizes disease intensity over time providing, at the same time, a quantitative measure of the pathogen virulence [55-57].

\section{Quantification of sporangia and leaf tissue colonization}

The samples inoculated with the $P$. viticola isolate $G$ were used to count the number of sporangia differentiated, to measure the colonized leaf areas and to quantify the pathogen DNA in each grapevine line at 9 dai. Sporangia were detached from the sporangiophores by vortexing each leaf disc in a $1.5 \mathrm{~mL}$ tube containing 500 
$\mu \mathrm{L}$ of distilled water. The average number of sporangia (SN) per leaf disc was calculated from the average number of sporangia per $\mathrm{mL}$ of suspension determined by counting the spores in two replicates of $10 \mu \mathrm{L}$ of sporangial suspension in a Neubauer counting chamber (Riechert Bright-Line haemocytometer, Hausser Scientific, Horsham, PA, USA) under a optical bright field microscope (Leitz Orthoplan). Sporangia were checked for viability by germination assays [58].

Immediately after the release of the sporangia from the leaf surface, the discs were fixed and cleared in $75 \%$ ethanol and kept at $4^{\circ} \mathrm{C}$. The samples were soaked in distilled water for 3 times, stained with $0.05 \%$ aniline blue in 0.067 $\mathrm{M} \mathrm{K}_{2} \mathrm{HPO}_{4}(\mathrm{pH} 9)$ for 24 hours and observed under a fluorescence microscope (Olympus BX50 equipped with a Q-Imaging Retiga 2000R digital camera; DAPI filter $\lambda$ exc 340-380 nm, dichroic mirror $400 \mathrm{~nm}$, barrier filter 435$485 \mathrm{~nm})$. The reaction of aniline blue with $\beta$-1,3-glucans, makes the fungal structures of $P$. viticola visible under UV light [59]. Pictures of the leaf discs colonized by the pathogen were captured at $4 \mathrm{x}$ magnification to measure the infected areas (IA). The areas in $\mathrm{mm}^{2}$ were estimated from the corresponding number of pixels measured with Adobe Photoshop 7.0 software (Adobe Systems Incorporated, San Jose, CA, USA).

\section{$P$. viticola DNA quantification}

The mycelial growth of $P$. viticola strain $G$ in the host tissues was estimated from the quantification of the pathogen DNA isolated from the leaf discs by using primers specific for the ITS (Internal Transcribed Spacer) region of the nuclear ribosomal DNA (rDNA) of P. viticola.

The leaf discs used for the colonization assessment under fluorescence microscope were rinsed in double distilled sterile water, ground in liquid nitrogen with the aid of mortar and pestle. The DNA, extracted following the protocol described by Toffolatti et al. [52], was resuspended in $40 \mu \mathrm{L}$ of double distilled sterile water. DNA from $P$. viticola sporangia $\left(2 \times 10^{5}\right.$ sporangia $)$ was used as a positive control and DNA from uninfected leaves as a negative control. DNA quality and quantity were spectrophotometrically checked (NanoDrop Technologies, Wilmington, DE). P. viticola DNA was serially diluted $(40,10,1,0.1,0.01,0.001,0.0001 \mathrm{ng} / \mu \mathrm{L})$ in water for the standard curve, or in $1 \mathrm{ng} / \mu \mathrm{L} V$. vinifera DNA, to investigate possible influences of the host DNA on the amplification of the pathogen DNA.

$P$. viticola primer sequences specific for the region between the internal transcribed spacer 1 (ITS 1) and the $5.8 \mathrm{~S}$ in the ITS sequence were used for the absolute quantification of the pathogen DNA by real-time PCR and Taqman chemistry as described by Valsesia et al. [60]. Reactions were performed in $30 \mu \mathrm{L}$ aliquots with $1 \mathrm{x}$ RealMasterMix probe $+\mathrm{ROX}$
(5 Prime GmbH, Hamburg, Germany), $900 \mathrm{nM}$ forward (TCCTGCAATTCGCATTACGT) and reverse (GGTTGCAGCTAATGGATTCCTA) primers, 250 nM 5'FAM-labeled probe quenched by 3'Tamra (TCGCAGTTCGCAGCGTTCTTCA), and $5 \mu \mathrm{L}$ of DNA template. $P$. viticola and $V$. vinifera DNA standards ranged from 0.005 to $200 \mathrm{ng}$. Real-time PCR was performed by the Applied Biosystems 7300 RealTime PCR System in MicroAmp optical 96-well plates sealed with optical adhesive covers (Life Technologies Italia, Monza, Italy). Thermal conditions consisted of $2 \mathrm{~min}$ at $50^{\circ} \mathrm{C}, 10 \mathrm{~min}$ at $95^{\circ} \mathrm{C}$ and 40 cycles of $95^{\circ} \mathrm{C}$ for $15 \mathrm{sec}$ and $60^{\circ} \mathrm{C}$ for $1 \mathrm{~min}$. Fluorescence emission was detected at the annealing/extension step $\left(60^{\circ} \mathrm{C}\right)$ and $\mathrm{ROX}$ was used as passive reference dye. Each PCR assay included negative controls (water and $1 \mathrm{ng} / \mu \mathrm{L} V$. vinifera DNA) and $P$. viticola DNA standards. Each reaction was run in duplicate. $\mathrm{Cqs}(\mathrm{Cq}=$ cycle number at which the fluorescence generated within a reaction crosses the threshold) were automatically calculated by the SDS software on the 7300 Real-Time PCR System. The standard curve was constructed by plotting Cqs against the logarithmic values of $P$. viticola DNA (ng): the correspondent DNA in the unknown samples $\left(\mathrm{X}_{0}\right)$ was calculated after linear regression analysis as $\mathrm{X}_{0}=10^{(\text {Ct-intercept }) / \text { slope }}$ whereas the PCR efficiency $(\mathrm{E})$ was calculated as $\mathrm{E}=10^{-1 / \text { slope }}-1$ [61].

\section{Histological analyses}

Young leaves detached from both the parental varieties and the corresponding hybrids were placed on WAK in Petri dishes, inoculated with numerous $10 \mu \mathrm{L}$ droplets of isolate $\mathrm{G}$ sporangial suspension and incubated as previously described. An analogous procedure was carried out using double-distilled, sterile water on the control leaves. The leaf areas under the droplets were collected from the inoculated and not-inoculated samples with a cork borer $(\varnothing 0.5 \mathrm{~cm})$ and kept in $75 \%$ ethanol at $4^{\circ} \mathrm{C}$. Both the callose deposition by the plant and the pathogen structures were investigated using aniline blue staining at 1, 2, 3, 4 and 7 dai. Hyphal length and diameter were measured at 2 and 2-4 dai respectively by analysing the images with Bel View software (BEL Engineering srl, Monza, Italy). The results were expressed as average values of three independent measures of three hyphae.

Nitrous acid reaction [62] was used for the detection of phenolic compounds between 1 and 7 dai, phloroglucinol$\mathrm{HCl}[37,63]$ for lignin at 7 and 15 dai and Neu's and Wilson's reagents for flavonoids at 5 and 10 dai [37]. The samples were mounted in $75 \%$ glycerol on glass slides and observed under bright field light microscopy (Olympus BX50), for phenols and lignin detection, or under UV light (Nikon Eclipse 80i equipped with a video-confocal system; 
Nikon Instruments S.p.a., Calenzano, FI, Italy) with DAPI filter, after staining for callose and flavonoids. The presence of autofluorescence was evaluated on unstained samples.

The association between the above mentioned defence metabolites and $P$. viticola structures was assessed by staining with aniline blue as described for the leaf tissues colonization. The pathogen structures were visualized in red, using DAPI filter, and the leaf tissues in green, using a FITC filter (ex 465-495 nm, dm $505 \mathrm{~nm}$, ba 515-555).

Histochemical visualization of POX under light microscopy was achieved by incubating the fixed leaf discs for $10 \mathrm{~min}$ in a medium containing $10 \mathrm{mg} \mathrm{TMB}$ (3,3,5,5'-Tetramethylbenzidine), $2.5 \mathrm{~mL}$ ethanol, $50 \mathrm{~mL}$ acetic acid/sodium acetate buffer solution $\mathrm{pH} 4.5,3 \mathrm{~mL}$ $3 \% \mathrm{H}_{2} \mathrm{O}_{2}$ and $47,5 \mathrm{~mL} \mathrm{H} \mathrm{H}_{2} \mathrm{O}$ [37]. The association of POX with the structures of $P$. viticola was confirmed by aniline blue staining of the tissues. Moreover, cytosolic POX was assessed by a spectrophotometric assay based on peroxidase reaction with hydrogen peroxide, using TMB as chromogenic substrate as described by Kortekamp and Zyprian [26]. The assay was carried out on two leaves of parental cultivars (Chardonnay and Bianca) and selected hybrid lines (18048, 18088, 18100, 18106, 18110 and 18120) inoculated with isolate G or distilled, sterile water. Six leaf discs were sampled per leaf and the assay was repeated twice. Basal POX was estimated from the extinction coefficients of the samples inoculated with water. The involvement of peroxidatic activity in grapevine- $P$. viticola interaction was evaluated taking into account $\Delta \mathrm{E}$, i.e. the difference between the spectrophotometric values obtained from the samples inoculated with the pathogen and those assessed in the uninoculated control leaves.

\section{Statistical analyses}

Upon satisfaction of the requirements for analysis of variance, AUDPC values were compared using one-way ANOVA and multiple comparison of the means (REGW-F test). A combined analysis of variance (twofactors ANOVA) was also carried out to test the interaction between strains and $\mathrm{cv} /$ hybrids (fixed factors).

Only for P. viticola strain G, each leaf disc was classified according to the average value of the class used to evaluate the disease severity in order to estimate the Gompertz growth model parameters by linear method on three replicates [64]. The pathogen fitness (PF) on each host genotype was evaluated from a composite index using a modified method of Flier and Turkensteen [65]: $P F=\frac{I E I \times S P O R}{T_{10} \times M G R} \times 10^{3}$ where IEI is the infection efficiency index, calculated as the fitted asymptotic value of disease severity at 10 dai; SPOR is the natural logarithm of the average number of sporangia per $\mathrm{cm}^{2}$ of infected leaf area; $\mathrm{T}_{10}$ is the time expressed in hours required for severity to reach 10\%; MGR is maximal curve growth rate, calculated as the first derivative of the fitted curve at the point of inflection; and $10^{3}$ is used for scaling purpose. Comparison of the mean values of the fitness components was carried out by non parametric statistics using Kruskal-Wallis test on the data transformed in ranks. ANOVA and multiple comparison of the mean PF values (REGW-F test) were performed to evaluate significant differences between the different grapevine varieties.

The existence of linear correlation among the amount of DNA (ng), sporangia and $\mathrm{mm}^{2}$ of infected area of each leaf disc inside the different grapevine lines at 7 dai was assessed by non parametric statistics Spearman's rho at the 0.05 level of significance.

The potential increase in POX as a response to the interaction with $P$. viticola was estimated by Wilcoxon signed-rank test for data pairs on the extinction coefficients of inoculated and not inoculated samples.

Statistical analysis was carried out with the SPSS Statistics 18.0 software.

\section{Abbreviations}

AUDPC: Area under disease progress curve; dai: Days after inoculation; DAPI: 4',6-diamidino-2-phenylindole; IA: Infected Area; IEl: Infection efficiency index; IR: Intermediate-resistant phenotype; IS: Intermediate-susceptible phenotype; MGR: Maximal growth rate; PF: Pathogen fitness; POX: Peroxidase activity; PSA: Percentage sporulating area index; QTL: Quantitative Trait Loci; SPOR: The natural logarithm of the average number of sporangia per $\mathrm{cm}^{2}$ of infected leaf area; $T_{10}$ : Time expressed in hours required for disease severity to reach 10\%; TMB: 3,3',5,5'- Tetramethylbenzidine; V: Variable phenotype; WAK: Water Agar Kinetin medium.

\section{Competing interests}

The authors declare that they have no competing interests.

\section{Authors' contributions}

ST carried out all the studies and drafted the manuscript, GV participated in the statistical analysis of the data and helped to draft the manuscript, DM helped to carry out microscopic examinations, AV conceived the study, participated in all steps of the analysis and drafted the manuscript. All authors read and approved the final manuscript.

\section{Acknowledgements}

The authors wish to thank Dr. Gabriele di Gaspero for providing the plant material, Lorenzo Cirio, Vera Di Clemente, Alessandra Frassini and Giuseppe Russo for their technical help, Prof. Graziano Zocchi and Dr. Gemma Assante for critical reading of the manuscript. This work was supported by the project 'Basi genetiche e fisiologiche della resistenza a peronospora nella vite (Vitis spp.)' granted by the Italian Ministry of University and Scientific Research (MIUR), PRIN 2006.

Received: 21 February 2012 Accepted: 5 July 2012

Published: 1 August 2012

\section{References}

1. This $P$, Lacombe $T$, Thomas MR: Historical origins and genetic diversity of wine grapes. Trends Genet 2006, 22:511-519.

2. Ingram DS: Physiology and Biochemistry of Host-Parasite Interaction. In The Downy Mildews. Edited by Spencer DM. New York: Academic Press; 1981:143-161.

3. Langcake $P$, Lovell PA: Light and electron microscopical studies of the infection of Vitis spp. by Plasmopara viticola, the downy mildew pathogen. Vitis 1980, 19:321-337. 
4. Lafon R, Bulit J: Downy Mildew of the Vine. In The Downy Mildews. Edited by Spencer DM. London: Academic Press; 1981:601-614.

5. Gisi U, Sierotzki $H$ : Fungicide modes of action and resistance in downy mildews. Eur J Plant Pathol 2008, 122:157-167.

6. Alleweldt G, Possingham JV: Progress in grapevine breeding. Theor Appl Genet 1988, 75:669-673.

7. Boubals D: Contribution a l'etude des causes de la resistance des Vitacees au mildiou de la vigne (Plasmopara viticola (B. et C.) Berl. et de T.) et leur mode de transmission hereditaire. Annales de l'Amelioration des Plantes 1959, 9:5-233.

8. Matthews P: Breeding for resistance to downy mildews. In The Downy Mildews. Edited by Spencer DM. London: Academic Press; 1981:255-287.

9. Blasi P, Blanc S, Wiedemann-Merdinoglu S, Prado E, Ruhl EH, Mestre $P$, Merdinoglu D: Construction of a reference linkage map of Vitis amurensis and genetic mapping of Rpv8, a locus conferring resistance to grapevine downy mildew. Theor App/ Genet 2011, 123:43-53.

10. Moreira FM, Madini A, Marino R, Zulini L, Stefanini M, Velasco R, Kozma P Grando MS: Genetic linkage maps of two interspecific grape crosses (Vitis spp.) used to localize quantitative trait loci for downy mildew resistance. Tree Genetics \& Genomes 2011, 7:153-167.

11. Welter L, Gokturk-Baydar N, Akkurt M, Maul E, Eibach R, Topfer R, Zyprian EM: Genetic mapping and localization of quantitative trait loci affecting fungal disease resistance and leaf morphology in grapevine (Vitis vinifera L). Molecular Breeding 2007, 20:359-374.

12. McDonald BA, Linde C: Pathogen population genetics, evolutionary potential, and durable resistance. Annu Rev Phytopathol 2002, 40:349-379.

13. StClair DA: Quantitative disease resistance and quantitative resistance loci in breeding. Annu Rev Phytopathol 2010, 48:247-268.

14. Pariaud B, Ravigné V, Halkett F, Goyeau H, Carlier J, Lannou C: Aggressiveness and its role in the adaptation of plant pathogens. Plant Pathology 2009, 58:409-424.

15. Zhan J, Mundt CC, Hoffer ME, McDonald BA: Local adaptation and effect of host genotype on the rate of pathogen evolution: an experimental test in a plant pathosystem. J Evol Biol 2002, 15:634-647.

16. Sotolár R: Comparison of grape seedlings population against downy mildew by using different provocation methods. Not Bot Hort Agrobot Cluj 2007, 35:61-68.

17. Di Gaspero G, Cipriani G: Resistance gene analogs are candidate markers for disease-resistance genes in grape (Vitis spp.). Theor Appl Genet 2002, 106:163-172.

18. Bellin D, Peressotti E, Merdinoglu D, Wiedemann-Merdinoglu S, AdamBlondon A-F, Cipriani G, Morgante M, Testolin R, Di Gaspero G: Resistance to Plasmopara viticola in grapevine 'Bianca' is controlled by a major dominant gene causing localised necrosis at the infection site. Theor Appl Genet 2009, 120:163-176.

19. Peressotti E, Wiedemann-Merdinoglu S, Delmotte F, Bellin D, Di Gaspero G, Testolin R, Merdinoglu D, Mestre P: Breakdown of resistance to grapevine downy mildew upon limited deployment of a resistant variety. BMC Plant Biol 2010, 10:147.

20. Casagrande K, Falginella L, Castellarin SD, Testolin R, Di Gaspero G: Defence responses in Rpv3-dependent resistance to grapevine downy mildew. Planta 2011, 234:1097-1109.

21. Sacristán S, García-Arenal F: The evolution of virulence and pathogenicity in plant pathogen populations. Mol Plant Pathol 2008, 9:369-384.

22. Leach JE, Vera Cruz CM, Bai J, Leung H: Pathogen fitness penalty as a predictor of durability of disease resistance genes. Annu Rev Phytopathol 2001, 39:187-224.

23. Glazebrook J: Contrasting mechanisms of defense against biotrophic and necrotrophic pathogens. Annu Rev Phytopathol 2005, 43:205-27.

24. Schulze-Lefert P: Knocking on the heaven's wall: pathogenesis of and resistance to biotrophic fungi at the cell wall. Curr Opin Plant Biol 2004 7:377-383.

25. Gindro K, Pezet R, Viret O: Histological study of the responses of two Vitis vinifera cultivars (resistant and susceptible) to Plasmopara viticola infections. Plant Physiol Biochem 2003, 41:846-853.

26. Kortekamp A, Zyprian E: Characterization of Plasmopara- resistance in grapevine using in vitro plants. J Plant Physiol 2003, 160:1393-1400

27. Barceló AR, Pomar F, López-Serrano M, Pedreño MA: Peroxidase: a multifunctional enzyme in grapevines. Funct Plant Biol 2003, 30:577-591.

28. Passardi F, Penel C, Dunand C: Performing the paradoxical: how plant peroxidases modify the cell wall. Trends Plant Sci 2004, 9:534-540.
29. Josephy PD, Eling T, Mason RP: The horseradish peroxidase-catalyzed oxidation of 3,5,3'5'-Tetramethylbenzidine. J Biol Chem 1982, 257:3669-3675.

30. Krieg R, Halbhuber K-J: Detection of endogenous and immuno-bound peroxidase - The status quo in histochemistry. Prog Histochem Cytochem 2010, 45:81-139.

31. Scott B, Eaton CJ: Role of reactive oxygen species in fungal cellular differentiations. Curr Opin Microbiol 2008, 11:488-493.

32. Adaskaveg JE: Defense mechanisms in leaves and fruit trees to fungal infection. In Defense mechanisms of woody plants against fungi. Edited by Blanchette RA, Biggs AR. Berlin: Springer-Verlag; 1992:107-245.

33. Kortekamp A, Wind R, Zyprian E: The role of callose deposits during infection of two downy mildew-tolerant and two-susceptible Vitis cultivars. Vitis 1997, 36:103-104.

34. Voigt CA, Somerville SC: Callose in biotic stress (pathogenesis) biology, biochemistry and molecular biology of callose in plant defence: callose deposition and turnover in plant-pathogen interactions. In Chemistry, Biochemistry, and Biology of 1-3 Beta Glucans and Related Polysaccharides. Edited by Bacic A, Fincher GB, Stone BA. London: Academic Press; 2009:525-562.

35. Vermerris W, Nicholson R: Phenolic compound biochemistry. Dordrecht: Springer; 2008.

36. Cruickshank IAM, Perrin DR: Pathological function of phenolic compounds in plants. In Biochemistry of phenolic compounds. Edited by Harborne JB. London: Academic Press; 1964:511-544.

37. Dai GH, Andary C, Mondolot-Cosson L, Boubals D: Histochemical studies on the interaction between three species of grapevine, Vitis vinifera, $V$. rupestris and $V$. rotundifolia and the downy mildew fungus, Plasmopara viticola. Physiol Mol Plant Pathol 1995, 46:177-188.

38. Langcake P: Disease resistance of Vitis spp. and the production of the stress metabolites resveratrol, $\boldsymbol{\epsilon}$-viniferin, $\mathbf{a}$-viniferin and pterostilbene. Physiol Plant Pathol 1981, 18:213-226.

39. Alonso-Villaverde V, Voinesco F, Viret O, Spring JL, Gindro K: The effectiveness of stilbenes in resistant Vitaceae: ultrastructural and biochemical events during Plasmopara viticola infection process. Plant Physiol Biochem 2010, 49:265-274.

40. Mattivi F, Vrhovsek U, Malacarne G, Masuero D, Zulini L, Stefanini M, Moser C, Velasco R, Guella G: Profiling of resveratrol oligomers, important stress metabolites, accumulating in the leaves of hybrid Vitis vinifera (Merzling $\times$ Teroldego) genotypes infected with Plasmopara viticola. J Agric Food Chem 2011, 59:5364-5375.

41. Kortekamp A, Wind R, Zyprian E: Investigation of the interaction of Plasmopara viticola with susceptible and resistant grapevine cultivars. J Plant Dis Protect 1998, 105:475-488.

42. Rogers $L A$, Campbell MM: The genetic control of lignin deposition during plant growth and development. New Phytol 2004, 164:17-30.

43. Hückelhoven R: Cell wall-associated mechanisms of disease resistance and susceptibility. Annu Rev Phytopathol 2007, 45:101-27.

44. Polesani M, Bortesi L, Ferrarini A, Zamboni A, Fasoli M, Zadra C, Lovato A Pezzotti M, Delledonne M, Polverari A: General and species-specific transcriptional responses to downy mildew infection in a susceptible (Vitis vinifera) and a resistant (V. riparia) grapevine species. BMC Genomics 2010, 11:117.

45. Gomès $E$, Coutos-Thévenot $P$ : Molecular aspects of grapevine-pathogenic fungi interactions. In Grapevine Molecular Physiology \& Biotechnology. 2nd edition. Edited by Roubelakis-Angelakis KA. Dordrecht: Springer; 2009:407-428

46. Liu SM, Sykes SR, Clingeleffer PR: Variation between and within grapevine families in reaction to leaf inoculation with downy mildew sporangia under controlled conditions. Vitis 2008, 47:55-63.

47. Pourcel L, Routaboul J-M, Cheynier V, Lepiniec L, Debeaujon I: Flavonoid oxidation in plants: from biochemical properties to physiological functions. Trends Plant Sci 2006, 12:29-36.

48. Walker JRL, Ferrar PH: Diphenol oxidases, enzyme-catalysed browning and plant disease resistance. Biotechnol Genet Eng Rev 1998, 15:457-498.

49. Dai GH, Andary C, Mondolot-Cosson L, Boubals D: Involvement of phenolic compounds in the resistance of grapevine callus to downy mildew (Plasmopara viticola). Eur J Plant Pathol 1995, 101:541-547.

50. Peterlunger E, di Gaspero G, Cipriani G, Sivilotti P, Zulini L, Marrazzo MT, Andreetta D, Testolin R: Breeding strategy for the introgression of disease resistance genes into European grapevine. Acta Horticulturae 2003, 603:665-670. 
51. Sobieszczuk-Nowicka E, Wieczorek P, Legocka J: Kinetin affects the level of chloroplast polyamines and transglutaminase activity during senescence of barley leaves. Acta Biochim Pol 2009, 56:255-259.

52. Toffolatti SL, Serrati L, Sierotzki H, Gisi U, Vercesi A: Assessment of Qol resistance in Plasmopara viticola oospores. Pest Manag Sci 2007, 63:194-20.

53. Towsend GR, Heuberger GW: Methods for estimating losses caused by disease in fungicide experiments. Plant Disease Reporter 1947, 27:340-343.

54. Shaner G, Finney RE: The effect of nitrogen fertilization on the expression of slow-mildewing resistance in knox wheat. Phytopathology 1977, 67:1051-1056.

55. Miller JS, Johnson DA, Hamm PB: Aggressiveness of isolates of Phytophthora infestans from the columbia basin of Washington and Oregon. Phytopathology 1998, 88:190-197.

56. Carson ML, Goodman MM, Williamson SM: Variation in aggressiveness among isolates of Cercospora from Maize as a potential cause of genotype-environment interaction in gray leaf spot trials. Plant Disease 2002, 89:1089-1093.

57. Hsiang T, Yang L, Barton W: Relative virulence of isolates of Sclerotinia homoeocarpa with varying sensitivity to propiconazole. Eur J Plant Pathol 1998, 104:163-169.

58. Burruano S, Alfonzo A, Lo Piccolo S, Conigliaro G, Mondello V, Torta L, Moretti M, Assante G: Interaction between Acremonium byssoides and Plasmopara viticola in Vitis vinifera. Phytopathol Mediterr 2008, 47:122-131.

59. Díez-Navajas AM, Greif C, Poutaraud A, Merdinoglu D: Two simplified fluorescent staining techniques to observe infection structures of the oomycete Plasmopara viticola in grapevine leaf tissues. Micron 2007, 38:680-683.

60. Valsesia G, Gobbin D, Patocchi A, Vecchione A, Pertot I, Gessler C: Development of a high-throughput method for quantification of Plasmopara viticola DNA in grapevine leaves by means of quantitative real-time polymerase chain reaction. Phytopathology 2005, 95:672-678.


gene quantity. Anal Biochem 2009, 284:1-10.

62. Reeve RM: Histochemical tests for polyphenols in plant tissues. Stain Technol 1951, 26:91-96.

63. Mollah MH, Gabor J, Barnavon L, Neuhaus JM, Mauch-Mani B. $\beta$-Aminobutyric acid-induced resistance against downy mildew in grapevine acts through the potentiation of callose formation and jasmonic acid signaling. Mol Plant Microbe Interact 2005, 18:819-829.

64. Madden LV, Hughes G, van den Bosch F: The study of plant disease epidemics. St. Paul: APS Press; 2007.

65. Flier WG, Turkensteen LJ: Foliar aggressiveness of Phytophthora infestans in three potato growing regions in the Netherlands. Eur J Plant Pathol 1999, 105:381-388.

doi:10.1186/1471-2229-12-124

Cite this article as: Toffolatti et al: Phenotypic and histochemical traits of the interaction between Plasmopara viticola and resistant or susceptible grapevine varieties. BMC Plant Biology 2012 12:124.

\section{Submit your next manuscript to BioMed Central and take full advantage of:}

- Convenient online submission

- Thorough peer review

- No space constraints or color figure charges

- Immediate publication on acceptance

- Inclusion in PubMed, CAS, Scopus and Google Scholar

- Research which is freely available for redistribution 